\title{
Penerapan Model View Controller Untuk Membangun Aplikasi Data Dasar Keluarga Desa Somagede
}

\author{
Andik Wijanarko', Adam Prayogo Kuncoro², Naufal Dzaki Wuryantoro ${ }^{3}$ \\ 1,2,3 Program Studi Informatika, Universitas Amikom Purwokerto \\ Jl. Letjend Pol. Soemarto Watumas, Kec. Purwokerto Utara, Kabupaten Banyumas, Indonesia

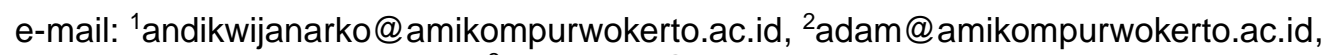 \\ ${ }^{3}$ dzaknoval@gmail.com
}

\begin{tabular}{llll}
\hline Informasi Artikel & Diterima: 17-07-2020 & Direvisi: 24-12-2020 & Disetujui: 13-01-2021
\end{tabular}

\begin{abstract}
Abstrak
Saat ini teknologi sudah banyak digunakan di berbagai sektor kehidupan, baik itu dibidang ekonomi, pendidikan, dan pemerintahan. Dengan perkembangan teknologi yang sangat pesat, instansi-instansi pemerintah dituntut untuk menerapkan sebuah pengolahan data yang terkompeterisasi sehingga dapat memberikan informasi yang tepat dan akurat. Salah satu contoh instansi pemerintahan adalah pemerintah desa. Pemerintahan Desa adalah penyelenggaraan urusan pemerintahan dan kepentingan masyarakat setempat dalam sistem pemerintahan Negara Kesatuan Republik Indonesia. Setiap desa memiliki catatan penduduk dan juga data dasar keluarga. Balai desa Somagede sudah memiliki sistem informasi pendataan data dasar keluarga desa Somagede. Pada saat petugas menggunakan sistem informasi pendataan data dasar keluarga Somagede, petugas mempunyai beberapa kendala yaitu, jaringan wifi di kantor desa tidak selalu ada, yang menyebabkan petugas merasa kesulitan untuk menginputkan data dasar keluarga Somagede dan menyajikan data dasar keluarga desa Somagede, kepada orang yang membutuhkan data dasar keluarga desa Somagede. Tujuan dari penelitian ini adalah untuk mengembangkan aplikasi pendataan data data dasar keluarga Somagede yang dapat diakses mempermudah petugas desa untuk melakukan pendataan data data dasar keluarga desa Somagede, tujuan lainnya adalah mengembangkan database aplikasi pendataan data dasar keluarga Somagede dari yang sederhana menjadi kompleks. Metode pengembangan perangkat lunak yang digunakan pada penelitian ini adalah extreme programming dengan MVC sebagai metode pemogramannya. Sedangkan pengujian menggunakan blackbox testing. Hasil dari aplikasi pendataan data dasar keluarga berbasis website ini adalah dapat memudahkan petugas dalam melakukan pendataan data dasar keluarga Somagede.
\end{abstract}

Kata kunci: pendataan penduduk, MVC, desa. \begin{tabular}{l} 
Abstract \\
Currently technology has been widely used in various sectors of life, be it in the fields of economy, \\
education and government. With the very rapid development of technology, government agencies are \\
required to implement a computerized data processing so that they can provide precise and accurate \\
information. One example of a government agency is the village government. Village Administration is \\
the implementation of government affairs and the interests of the local community in the government \\
system of the Unitary State of the Republic of Indonesia. Each village has population records as well \\
as basic family data. Somagede village hall already has a basic data collection information system for \\
Somagede village families. When the officer used the Somagede family's basic data collection \\
information system, the officer had several obstacles, namely, the wifi network at the village office was \\
not always available, which caused the officers to find it difficult to input Somagede's family basic data \\
and present the Somagede village family's basic data to people who needed it. basic data of \\
Somagede village families. The purpose of this study was to develop a data collection application for \\
the Somagede family that can be accessed to make it easier for village officials to collect data on the \\
basic data of the Somagede family, another goal is to develop a database of basic data collection \\
applications for the Somagede family from simple to complex. The software development method \\
used in this research is extreme programming with MVC as the programming method. While testing \\
\hline
\end{tabular}

This work is licensed under a Creative Commons Attribution-ShareAlike 4.0 International License. 
uses blackbox testing. The result of this website-based family data collection application is that it can make it easier for officers to collect basic data on the Somagede family.

Keywords : population data collection, village, MVC

\section{Pendahuluan}

Administrasi Kependudukan adalah rangkaian kegiatan penataan dan penertiban dalam penerbitan dokumen dan Data Kependudukan melalui Pendaftaran Penduduk, Pencatatan Sipil, pengelolaan informasi Administrasi Kependudukan serta pendayagunaan hasilnya untuk pelayanan publik dan pembangunan sektor lain (Negeri, 2013). Administrasi kependudukan menjadi sangat penting karena selalu bersentuhan dengan setiap aktivitas, diantaranya adalah saat pemilu kepala daerah, mengurus suratsurat kendaraan, mengurus surat-surat tanah, dan aktivitas lainnya. Administrasi kependudukan merupakan tanggung jawab pemerintah kota / kabupaten, dengan desa / kelurahan sebagai awal pendaftaran kependudukan dan administrasi kependudukan. Dalam pendaftaran kependudukan dan administrasi kependudukan perlu dilakukan dengan cepat, tepat, dan benar agar penduduk sebagai pelanggan merasakan pelayanan yang memuaskan (Wati et al., 2018).

Desa adalah kesatuan masyarakat hukum yang memiliki batas wilayah yang berwenang untuk mengatur dan mengurus urusan pemerintahan, kepentingan masyarakat setempat berdasarkan prakarsa masyarakat, hak asal usul, dan / atau hak tradisional yang diakui dan dihormati dalam system pemerintahan Negara Kesatuan Republik Indonesia. Pemerintahan Desa adalah penyelenggaraan urusan pemerintahan dan kepentingan masyarakat setempat dalam sistem pemerintahan Negara Kesatuan Republik Indonesia. Pemerintah Desa adalah Kepala Desa atau yang disebut dengan nama lain dibantu perangkat Desa sebagai unsur penyelenggara Pemerintahan Desa. Desa memerlukan data profil desa dan kelurahan untuk mengetahui gambaran potensi dan tingkat perkembangan desa dan kelurahan (RI, 2007). Profil desa dan kelurahan adalah gambaran menyeluruh tentang karakter desa dan kelurahan yang meliputi data dasar keluarga, potensi sumber daya alam, sumber daya manusia, kelembagaan, prasarana dan sarana serta perkembangan kemajuan dan permasalahan yang dihadapi desa dan kelurahan. Data dasar keluarga adalah gambaran menyeluruh potensi dan perkembangan keluarga yang meliputi potensi sumber daya manusia, perkembangan kesehatan dan pendidikan, penguasaan asset ekonomi dan sosial keluarga, partisipasi anggota keluarga dalam proses pemerintahan, pembangunan dan kemasyarakatan serta berbagai permasalahan kesejahteraan keluarga dan perkembangan keamanan dan ketertiban di lingkungannya (RI, 2007).

Balai Desa Somagede sudah memiliki sistem informasi pendataan data dasar keluarga berbasis website. Pada saat petugas menggunakan sistem informasi pendataan data dasar keluarga, petugas mempunyai beberapa kendala yaitu, jaringan wifi di kantor desa tidak selalu ada, yang menyebabkan petugas merasa kesulitan untuk menginputkan data dasar keluarga dan menyajikan data dasar keluarga, kepada orang yang membutuhkan data dasar keluarga desa Somagede. Selain itu terdapat data dasar keluarga yang belum lengkap yaitu, data kelembagaan, data hasil pekerjaan dan lain-lain.

Berdasarkan dari kendala-kendala yang telah dijabarkan, kantor Desa Somagede mengharapkan adanya pengembangan pada aplikasi pendataan data dasar keluarga berbasis offline dengan melakukan pengembangan database pada aplikasi pendataan data dasar keluar pada desa Somagede. Dikarenakan tidak ada fasilitas untuk mengembangkan aplikasi tersebut dari pihak pemerintah kabupaten atau kota

Pengembangan perangkat lunak dibuat dengan standar tententu sehingga dapat dikembangkan oleh programmer lain. Salah satu standar dalam pengembangan perangkat lunak terutama dalam pengkodean adalah penggunaan metode Model View Controller (MVC) (Simanjuntak \& Kasnady, 2016) yang merupakan metode paling populer saat ini (Diana \& Febrianti, 2017). Model ini memisahkan code dalam tiga kelompok yaitu kelompok model, view dan controller (SY \& Rismayani, 2016). Kelompok model bias any merupakan kode aplikasi yang berhubungan dengan database, sedangkan view yang berhubungan dengan tampilan atau user interface dan kelompok controller adalah kodekode pengendali Model dan View (Wismarini \& Murti, 2018). Dengan metode MVC ini, lebih mudah dalam pengelolaan kode program (Destiningrum \& Adrian, 2017), misalnya jika bermasalah dengan user interface, maka hanya perlu memperhatikan bagian View (Hidayat, 2012) . Saat ini telah banyak framework untuk 
mempermudah penggunaan metode MVC. Framework-frameword tersebut diantaranya adalah Code Igniter (Cl) (Afuan, 2010)(Prabowo, 2015)(Muzakir, 2014), Laravel (Luthfi, 2017)(Erinton et al., 2017)(Yudanto et al., 2017), Yii (Jannah et al., 2015)(Sucipto \& Hermawan, 2017)(Ariansyah \& Josi, 2017) dan sebagainya.

\section{Metode Penelitian}

1. Waktu Penelitian

Penelitian ini dilaksanakan degan berlokasi di kantor desa Somagede. Kantor desa Somagede tersebut beralamat di Dusun I, Somagede, Cilongok, Kabupaten Banyumas, Jawa Tengah 53162, Indonesia. Penelitian ini dilakukan pada bulan April 2019 - Juli 2019.

\section{Metode Pengumpulan Data}

Dalam penelitian dibutuhkan data pendukung yang diperoleh dengan suatu metode pengumpulan data yang relevan. Adapun tahapan pengumpulan data yang digunakan pada penelitian ini menggunakan wawancara, studi pustaka, dan observasi

\section{Konsep Penelitian}

Dalam penyusunan penelitian ini, kerangka kerja penelitian yang digunakan terlihat pada gambar 1

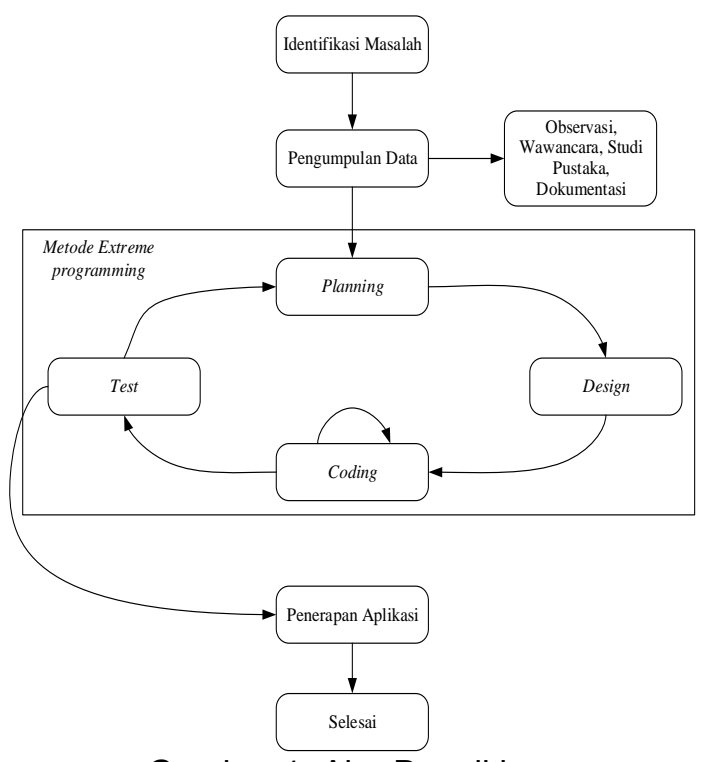

Gambar 1. Alur Penelitian

Penelitian ini memiliki tujuan membuat aplikasi pendataan data dasar keluarga dengan menggunakan konsep model view controller $(M V C)$. Pada penelitian ini, untuk membuat aplikasi pendataan data dasar keluarga akan menggunakan metode extreme programming $(X P)$. Model ini menyediakan pendekatan perangkat lunak yang berurutan yaitu tahap planning, tahap design, tahap coding, tahap testing.

Extreme Programming merupakan sebuah proses rekayasa perangkat lunak yang cenderung menggunakan pendekatan berorientasi objek dan sasaran dari metode ini adalah tim yang dibentuk dalam skala kecil sampai medium serta metode ini juga sesuai jika tim dihadapkan dengan requirement yang tidak jelas maupun terjadi perubahanperubahan requirement yang sangat cepat (Supriyatna \& Adi, 2018). Skema model XP dapat dilihat pada gambar 2 .

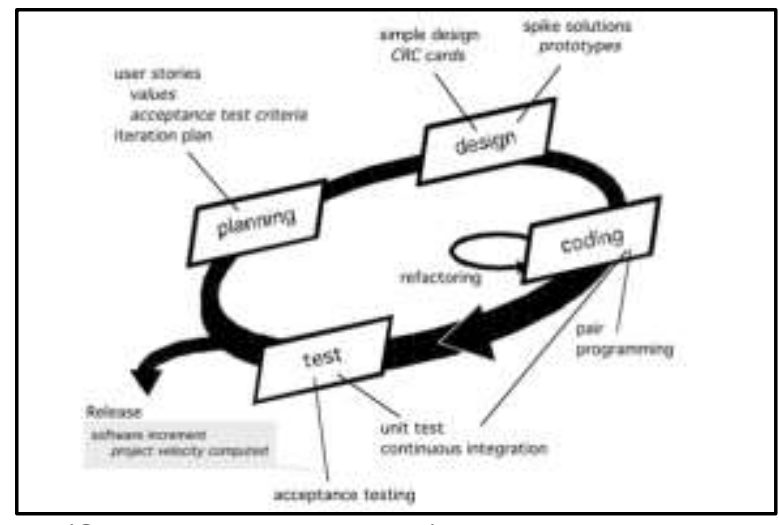

(Supriyatna \& Adi, 2018)

\section{Gambar 2. Extreme Programming}

\section{Hasil dan Pembahasan}

1. Gambaran Objek Penelitian

Desa Somagede adalah Desa di Kecamatan Cilongok, Kabupaten Banyumas, Provinsi Jawa Tengah, Indonesia. Desa Somagede merupakan salah satu desa yang secara administrasi memiliki wilayah hutan negara yang dikelola oleh Perhutani Resort Pemangkuan Hutan (RPH) Karanggandul, Bagian Kesatuan Pemangkuan Hutan (BKPH) Gunung Slamet Barat, Kesatuan Pemangkuan Hutan (KPH) Banyumas Timur, Unit I Jawa Tengah. Jarak Desa Somagede dari ibu kota kecamatan Cilongok kurang lebih 10 kilometer arah utara dengan waktu tempuh sekitar 15 menit, dari ibu kota kabupaten Banyumas (Purwokerto) kurang lebih 20 kilometer arah Barat Laut, dapat ditempuh dengan kendaraan (motor, mobil) selama 30 menit.

\section{Metode Pengembangan Sistem}

\section{a. Planning}

Tahap planning merupakan tahapan awal dari metode extreme programming pada penelitian ini. Pada tahap ini, peneliti melakukan analisa secara intensif terhadap kebutuhan pengguna dan kebutuhan sistem untuk pembuatan aplikasi profil desa 
Somagede, agar aplikasi dapat dipahami aplikasi seperti apa yang dibutuhkan oleh pengguna berdasarkan teknik pengumpulan data yang telah dilakukan yaitu wawancara.

\section{b. Design}

Tahap design adalah proses yang fokus pada desain pembuatan program sistem. Tahap ini mengubah kebutuhan sistem dari tahap analisis kebutuhan ke penerapan desain agar dapat diimplementasikan menjadi program pada tahap selanjutnya. Pada tahap design peneliti menggunakan metode unified modelling language (UML).

Langkah awal pada UML adalah Use Case. Pada diagram use case ini dipakai untuk mengetahui fungsi apa yang ada di dalam sebuah sistem informasi dan siapa saja yang berhak menggunakan fungsi - fungsi pada suatu aplikasi.

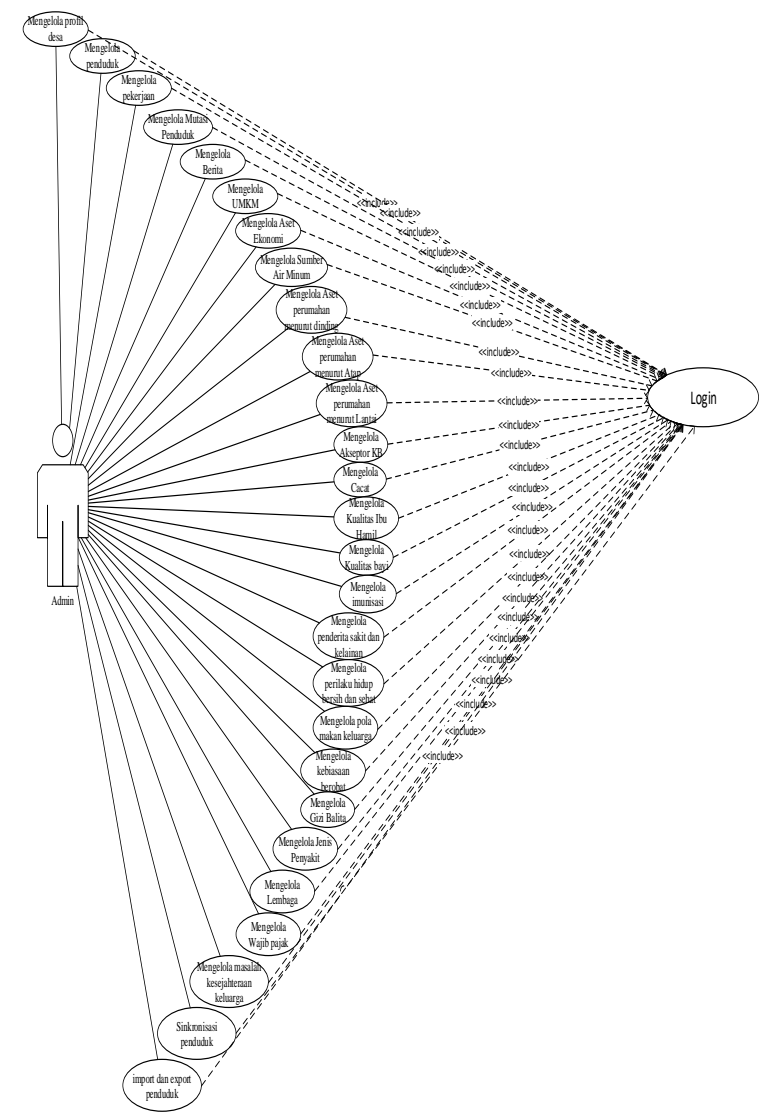

Gambar 3. Use case diagram

Langkah selanjutnya adalah dengan membuat Activity Diagram yang digunakan untuk menggambarkan workflow (aliran kerja) atau sebuah aktifitas dari sebuah sistem (menu) yang berada di perangkat lunak. Diagram ini adalah sebuah penggambaran aktifitas bukan apa yang dilakukan oleh aktor, jadi aktifitas ini yang akan dilakukan oleh sistem. Activity Diagram pada system ini dapat dilihat pada gambar 4.

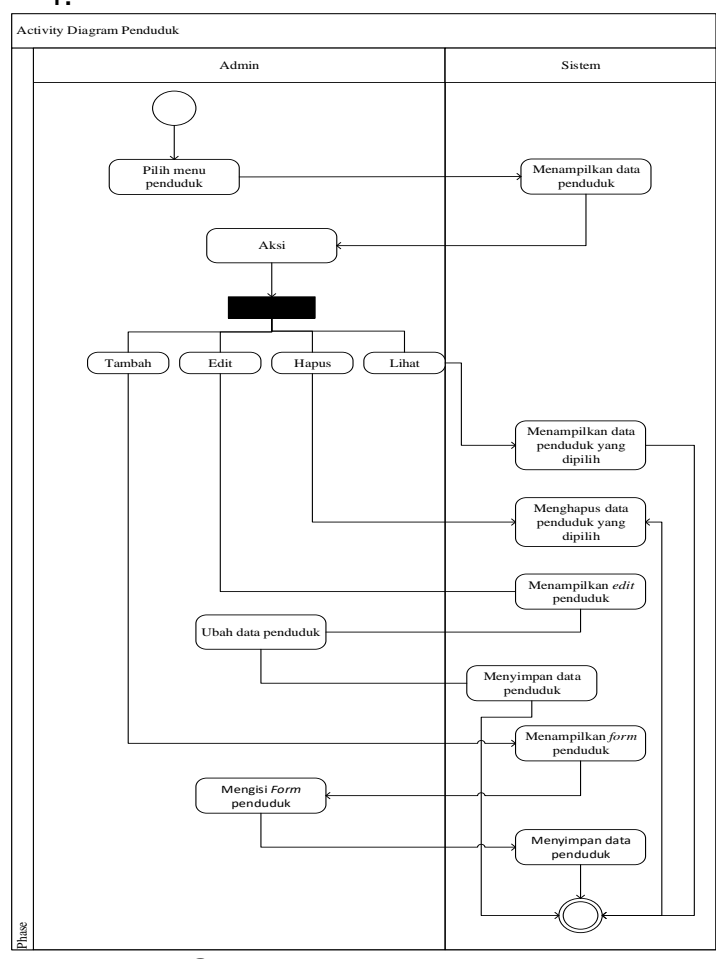

Gambar 4. Activity diagram

Setelah activity diagram, langkah selanjutnya adalah dengan membuat sequence diagram. Diagram sekuan ini digunakan untuk menggambarkan kelakuan objek pada use case dengan cara mendeskripsikan waktu hidup objek dan message yang dikirimkan dan diterima antar objek Skema Activity diagram dapat dilihat pada gambar 5 .

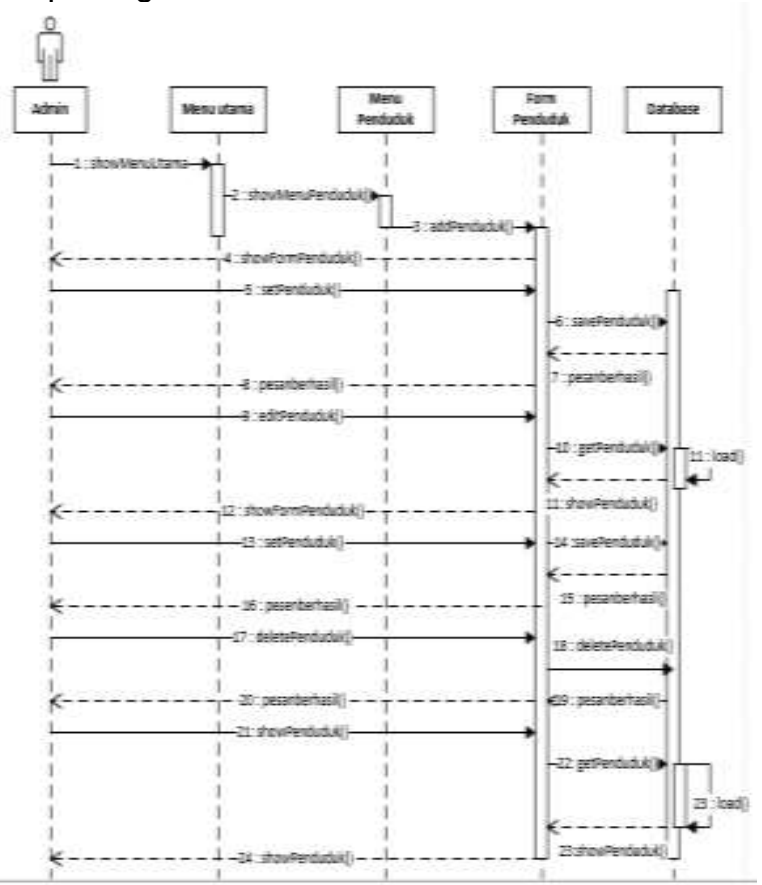

Gambar 5. Sequence diagram 


\section{c. Development}

Pada tahap ini peneliti menghasilkan program komputer berdasarkan desain yang sudah dibuat sebelumnya dengan menggunakan bahasa pemrograman PHP (Hypertext Preproccessor) dan database MYSQL dengan MVC sebagai metode pemrogramannya, serta hasil dari tahap ini akan masuk ke tahap pengujian.

Framework MVC yang dipergunakan adalah Codeingniter dengan pengaturan fungsi folder sebagai berikut.

1) Models

Fungsi Model dipergunakan untuk pengelolaan basis data dasar yang terhubung ke basis data mysql. file-file yang dimasukkan pada folder Models ini antara lain M_aset.php, M_aset_ekonomi.php, M_air.php, M_berobat.ph $p$ dan sebagainya. setiap file diawali dengan huruf $M$ untuk mempermudah dalam pengelolaannya. screenshot dari folder Models dapat dilihat pada gambar 6 .

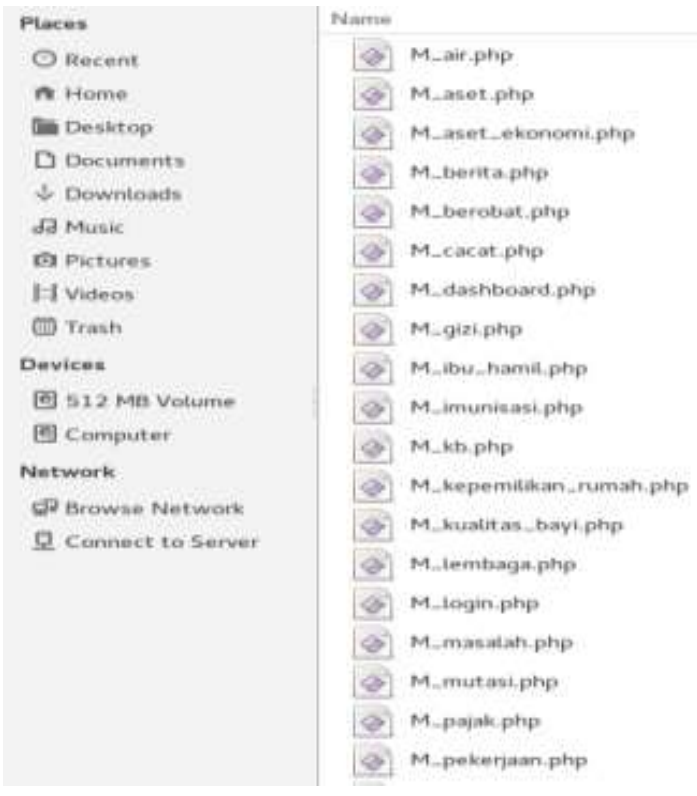

Gambar 6. file pada folder Models

2) Views

Views dipergunakan meletakkan untuk filefile yang berfungsi sebagai tampilan atau antarmuka aplikasi. screenshot file-file yang terdapat dalam forlder Views adalah sebagai berikut

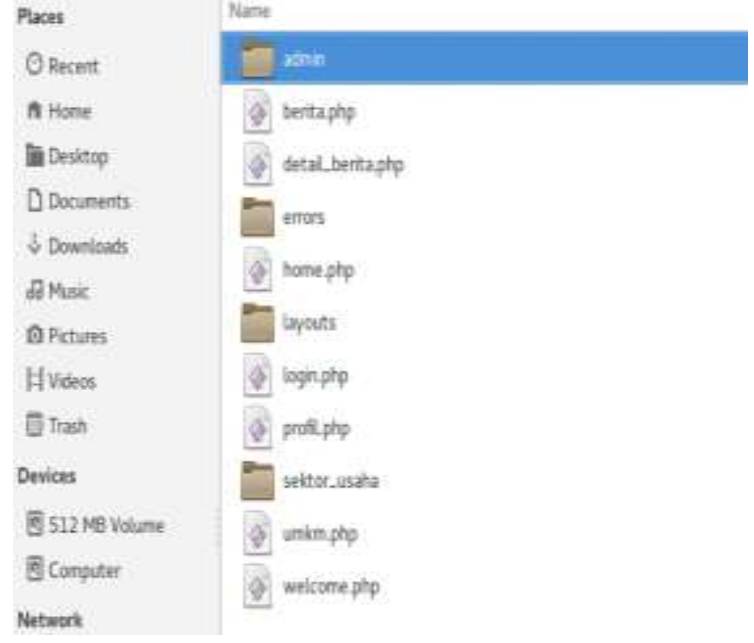

Gambar 7. file pada folder Views

dari gambar di atas dapat dijelaska bahwa folder admin berisi file-file tampilan untuk admin, folder errors berisi tampilan dari berbagai kemungkinan kesalahan yang terjadi, folder layout berisi file-file tampilan untuk yang selain admin sedangkan untuk folder sektor_usaha adalah tampilan khusus sektor usaha, hal ini karena data sektor usaha sering dijadikan sebagi bahan survei atau laporan dengan format yang berbedabeda sehingga perlu dibuat folder khusus untuk mempermudah pengelolaan

3) Controller

Folder Controller berfungsi untuk meletakkan folder yang dipergunakan sebagai folder untuk meletakkan file-file yang berfungsi sebagai penghubung antara model dan view. screenshot dari file-file yang dalam folder Controller dapat dilihat pada tampilan beikut

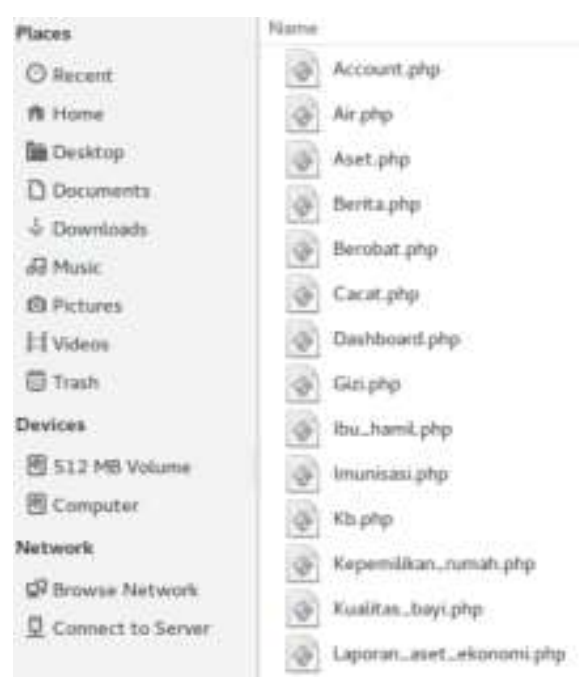

Gambar 8. file pada folder Models

Development awal adalah tentang halaman admin. Halaman ini merupakan 
dashboard dari aplikasi ini. Pada halaman ini admin dapat melakukan control terhadap seluruh fungsi-fungsi aplikasi. Gambar dari hasil develop halaman admin dapat dilihat pada gambar 9 .

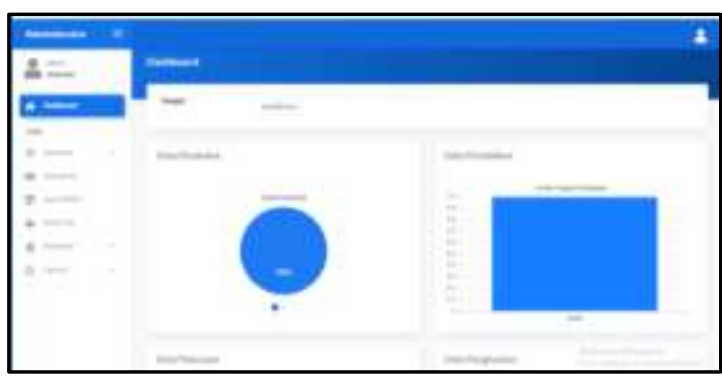

Gambar 9. Halaman Admin

Setelah halaman admin dibuat, langkah selanjutnya adalah membuat halaman penduduk. Halaman ini berfungsi untuk mengolah data penduduk. Tampilan halaman penduduk dapat dilihat pada gambar 10 ..

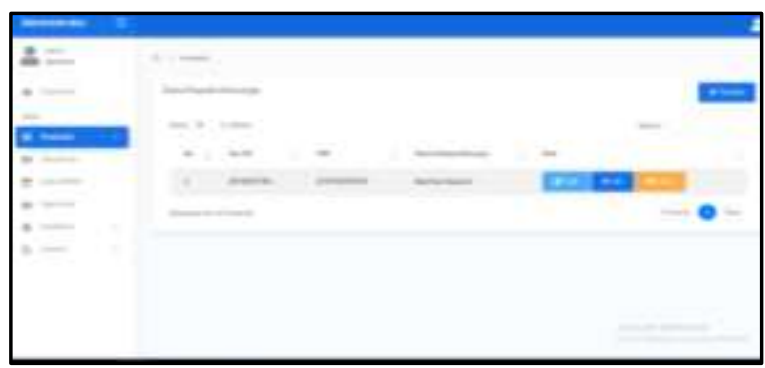

Gambar 10. Halaman Penduduk

Halaman penduduk merupakan halaman untuk mengelola data penduduk, salah satu diantaranya adalah untuk memasukkan datadata penduduk. Tampilan halaman untuk memasukkan data penduduk dapat dilihat pada gambar 11.

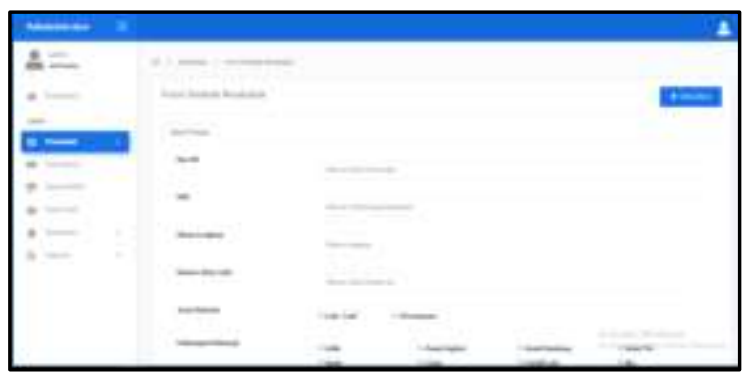

Gambar 11. Halaman input data penduduk

Dalam pengelolaan data penduduk, hal utama yang perludibangun adalah fasilitas print out data penduduk. Dengan adanya fasilitas ini, pejabat dapat membuat laporan data penduduk ketika terjadi pendataan data secara hard copy. Tampilan halaman pembuatan laporan data penduduk dapat dilihat pada gambar 12

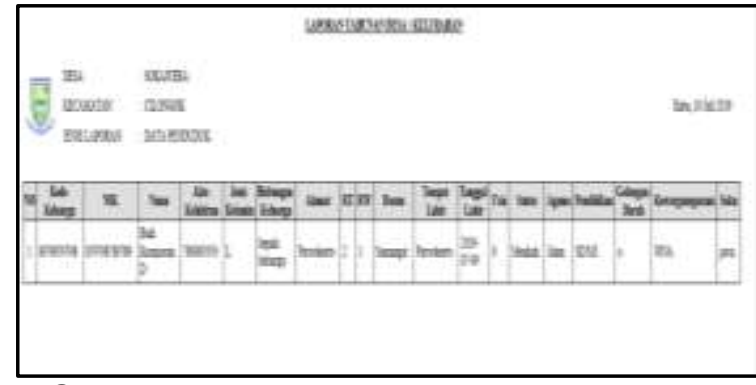

Gambar 12. Halaman laporan data penduduk

Salah satu tujuan utama pada pembangunan perangkat lunak hasil kegiatan penelitian ini adalah penerapan metode MVC dalam pemrograman sehingga menghasilkan perangkat lunak yang akan dipergunakan untuk pendataan data dasar keluarga beserta dengan data usaha mikro kecil dan menengah (UMKM) tiap keluarga di desa Somagede. Tampilan dari halaman pendataan UMKM ini adalah sebagai berikut.

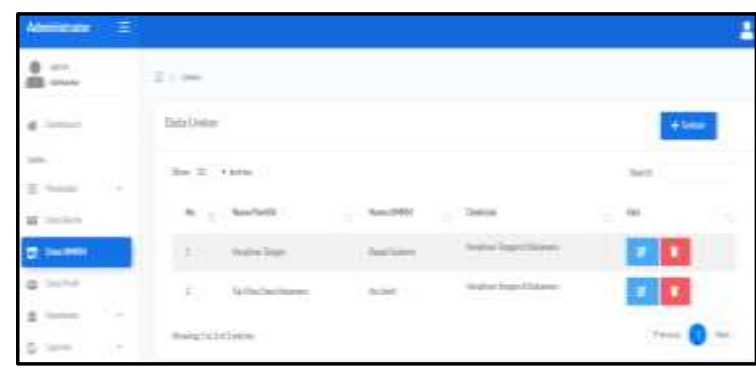

Gambar 12. Halaman Pendataan UMKM

\section{d. Testing Aplikasi}

Pada tahap ini peneliti melakukan pengujian blackboxtesting. Pengujian blackbox yaitu menguji perangkat lunak dari segi spesifikasi fungsional tanpa meguji desain dan kode program. Hasil pengujian dari blackbox testing yang dilakukan peneliti adalah aplikasi pendataan data dasar keluarga dapat mempermudah petugas desa.

\begin{tabular}{|c|c|c|c|}
\hline \multirow[t]{2}{*}{ No } & \multicolumn{3}{|c|}{ Kategori Tes } \\
\hline & $\begin{array}{c}\text { Fungsi } \\
\text { Aplikasi }\end{array}$ & Indikator & Hasil \\
\hline 1 & $\begin{array}{l}\text { Pengelolaa } \\
\text { n data } \\
\text { Penduduk }\end{array}$ & $\begin{array}{l}\text { Fungsi CRUD } \\
\text { dapat berjalan } \\
\text { dengan baik }\end{array}$ & Sesuai \\
\hline 2 & $\begin{array}{l}\text { Pengelolaa } \\
\text { n data } \\
\text { UMKM }\end{array}$ & $\begin{array}{l}\text { Fungsi CRUD } \\
\text { dapat berjalan } \\
\text { dengan baik }\end{array}$ & Sesuai \\
\hline 3 & $\begin{array}{l}\text { Laporan } \\
\text { Penduduk }\end{array}$ & $\begin{array}{l}\text { Tampil laporan } \\
\text { penduduk dan } \\
\text { bisa download } \\
\text { pdf }\end{array}$ & Sesuai \\
\hline 4 & $\begin{array}{l}\text { Laporan } \\
\text { UMKM }\end{array}$ & $\begin{array}{l}\text { Tampil laporan } \\
\text { UMKM dan } \\
\text { dapat } \\
\text { didownload PDF }\end{array}$ & Sesuai \\
\hline
\end{tabular}




\section{Kesimpulan}

Berdasarkan hasil dari penelitian yang telah dilakukan penulis dalam membangun perangkat lunak menggunakan metode MVC dalam penelitian ini, dapat ditarik kesimpulan:

1. Hasil penelitian yang dilakukan sudah berhasil membangun aplikasi pendataan data dasar keluarga desa Somagede dengan menggunakan frameworkcodeigniter yang mampu untuk membantu petugas desa Somagede untuk mengelola data profil desa Somagede.

2. Hasil penelitian yang telah dilakukan telah berhasil mengembangkan database dari aplikasi data dasar keluarga desa Somagede yang sederhana menjadi database yang lebih kompleks.

3. Hasil pengujian aplikasi yang dilakukan menggunakan blackboxtesting adalah aplikasi dapat mempermudah petugas desa dalam melakukan pendataan data dasar keluarga.

\section{Ucapan Terima Kasih}

Ucapan terima kasih peneliti sampaikan kepada Universitas Amikom Purwokerto yang telah mendanai kegiatan penelitian ini dengan program Penelitian Dosen Pemula tahun anggaran 2019.

\section{Referensi}

Afuan, L. (2010). Pemanfaatan Framework Codeigniter Dalam Pengembangan Sistem Informasi Pendataan Laporan Kerja Praktek Mahasiswa Program Studi Teknik Informatika Unsoed. JUITA, I(2), 39-44.

Ariansyah, \& Josi, A. (2017). Pengembangan Framework Yii Dalam Pembangunan Sistem Inventaris Stmik Prabumulih Dengan Konsep User Centered Design ( UCD ). Jurnal Informatika: Jurnal Pengembangan IT (JPIT), 03(01), 26-30.

Destiningrum, M., \& Adrian, Q. J. (2017). Sistem Informasi Penjadwalan Dokter Berbassis Web Dengan Menggunakan Framework Codeigniter ( Studi Kasus: Rumah Sakit Yukum Medical Centre ). Jurnal TEKNOINFO, 11(2), 30-37.

Diana, \& Febrianti. (2017). Implementasi Model View Controller(Mvc) Pada Aplikasi Doa Harian Untuk Anak Muslim Berbasis Android. Jurnal Informatika, 17(1), 11-21.

Erinton, R., Negara, R. M., \& Sanjoyo, D. D. (2017). Analisis Performasi Framework Codeigniter Dan Laravel Menggunakan Web Server Apache. E-Proceeding Of Engineering, 4(3), 3565-3572.

Hidayat, A. (2012). Penerapan Arsitektur Model
View Controller ( MVC ) Dalam Perancangan Ekstensi Sebuah Content Management System. Jurnal Teknologi Informasi Dan Komunikasi, 3(1), 17-22.

Jannah, E. N., Masrur, M., \& Asiyah, S. (2015). Penerapan Framework Yii Dalam Pembangunan Sistem Informasi Asrama Santri Pondok Pesantren Sebagai Media Pencarian Asrama Berbasis Web. Journal Of Information Systems Engineering And Business Intelligence, 1(2), 49-58.

Luthfi, F. (2017). Penggunaan Framework Laravel Dalam Rancang Bangun Modul Back-End Artikel Website Bisnisbisnis.ID. JISKA, 2(1), 34-41.

Muzakir, A. R. I. (2014). Implementasi Manajemen Perpustakaan Menggunakan Framework Implementasi Manajemen Perpustakaan Menggunakan Framework Codeigniter ( $\mathrm{Cl}$ ) Dengan Teknik Hierarchical Model - View - Controller. Seminar Nasional Sains Dan Teknologi Informasi 2014 (Senasti 2014), Mei.

Negeri, K. D. (2013). Undang-Undang No. 24 Tahun 2013 Tentang Perubahan Atas Undang-Undang Nomor 23 Tahun 2006 Tentang Administrasi Kependudukan.

Prabowo, D. (2015). Website E-Commerce Menggunakan Model View Controller ( MVC) Dengan Framework Codeigniter Studi Kasus: Toko Miniatur Pendahuluan Landasan Teori. Jurnal IImiah DASI, 16(1), 23-29.

RI, K. D. N. (2007). Peraturan Menteri Dalam Negeri Nomor 12 Tahun 2007.

Simanjuntak, P., \& Kasnady, A. (2016). ANALISIS MODEL VIEW CONTROLLER ( MVC ) PADA. Jurnal ISD, 2(2), 56-66.

Sucipto, A., \& Hermawan, I. D. (2017). Sistem Layanan Kesehatan Puskesmas Menggunakan Framework YII ( Studi Kasus: Puskesmas Kalirejo Pesawaran ). Jurnal TEKNOKOMPAK, 11(2), 61-65.

Supriyatna, \& Adi. (2018). Metode Extreme Programming Pada Pembangunan Web Aplikasi Seleksi Peserta Pelatihan Kerja. Jurnal Teknik Informatika.

SY, H., \& Rismayani. (2016). Penerapan Konsep MVC Pada Aplikasi Web Menggunakan Framework Laravel. Prosiding Seminar IImiah Sistem Informasi Dan Teknologi Informasi, December.

Wati, Masna, \& Despahari, E. (2018). Sistem Informasi Pelayanan Administrasi Kependudukan Dan Catatan Sipil Kelurahan Di Kecamatan Marangkayu Kutai Kartanegara. Jurnal Rekayasa Teknologi Informasi, 2(1).

Wismarini, D., \& Murti, H. (2018). Penggunaan Model View Controller (Mvc) Dalam 
Perancangan Model Aplikasi Webgis Untuk Informasi Rentan Banjir Di Semarang. Prosiding SINTAK, 458-464.

Yudanto, A. L., Tolle, H., \& Brata, A. H. (2017).

Rancang Bangun Aplikasi Sistem
Informasi Manajemen Laboratorium Biomedik Fakultas Kedokteran Universitas Brawijaya. Jurnal Pengembangan Teknologi Informasi Dan IImu Komputer, 1(8), 628-634. 